\title{
ANALISA KINERJA RUAS JALAN KARET DI KOTA PALANGKA RAYA
}

\author{
Faizal Candra Prasetyo ${ }^{(1)}$, Nirwana Puspasari ${ }^{(2)}$, Rida Respati ${ }^{(3)}$ \\ Alumni Fak.Teknik UM Palangka Raya(1) \\ Program Studi Teknik Sipil UM Palangka Raya(2)(3)
}

\begin{abstract}
ABSTRAK
Perkembangan dan pertumbuhan pada berbagai aspek kehidupan dan kemajuan dalam pembangunan, memberi dampak terhadap bertambahnya jumlah kendaraan bermotor. Hal ini akan mengakibatkan jumlah arus lalu lintas meningkat, sementara kemampuan jalan terbatas untuk melayani. Peningkatan arus lalu lintas yang terjadi pada suatu jalan akan mempengaruhi terhadap kapasitas dan kinerja jalan itu sendiri sepanjang ruas jalan karet memiliki kegiatan lalu lintas yang cukup banyak. Berdasarkan kondisi yang demikian maka dipandang perlu untuk mengadakan penelitian untuk mengetahui apakah ada masalah kapasitas dan kinerja jalan pada jalan tersebut.

Untuk mendapatkan data peneliti harus langsung kelapangan untuk mendapatkan data lalu lintas yang dilakukan selama tiga hari. Setelah mendapatkan data volume lalu lintas maka data tersebut diolah sehingga didapatlah hasil, dimana hasil itu berupa angka untuk mengetahui apakah kapasitas dan kinerja jalan tersebut bermasalah atau tidak menurut aturan MKJI 1997.

Dari hasil penelitian yang dilakukan maka didapat hasil bahwa kinerja jalan karet DS pagi 368.56/1247.62 $=0.30$, siang 473.93/1290.15 =0.39, sore 492.28/1332.68 $=040$ masih dalam keadaan baik.
\end{abstract}

Kata kunci: Analisa, Kinerja Ruas, Lalu lintas 
Analisa Kinerja Ruas Jalan Karet..., Faizal ${ }^{(1)}$, Nirwana ${ }^{(2)}$, Rida $^{(3)}$

\section{PENDAHULUAN}

Perkembangan suatu wilayah sangat diperlukan oleh sistem transportasi, karena sistem transportasi menyangkut pergerakan manusia dan barang. Perencanaan transportasi memiliki peranan sangat penting terhadap perkembangan sosial ekonomi masyarakat.

Kota Palangka Raya sebagai ibukota propinsi Kalimantan Tengah juga berfungsi sebagai pusat perdagangan, pusat kegiatan industri, pusat kegiatan pariwisata, modatransportasiyang digunakan khususnya di Kota Palangkaraya adalah transportasi darat karena cukup efektif, ekonomis dan efisien, transportasi darat ini cukup penting untuk mengembangkan potensi ekonomi, sosial politik dan budaya bahkan merupakan sarana dalam membangun suatu wilayah secara keseluruhan.

\section{Latar Belakang}

Perkembangan dan pertumbuhan pada berbagai aspek kehidupan termasukkemajuan dalam pembangunan memberi dampak terhadap bertambahnya jumlah kendaraan bermotor. Hal ini akan mengakibatkan jumlah arus lalu lintas meningkat, sementara kemampuan jalan terbatas untuk melayanipertambahanini.

\section{Perumusan Masalah}

1. Berapakah volume dan kapasitas dari ruas jalan Karet?

2. Berapakahderajat kejenuhan dari jalan Karet?

\section{Tujuan Penelitian}

1. Untuk mendapatkan volume dan kapasitas dari ruas jalan Karet.

2. Untukmengetahui derajat kejenuhan dari jalan Karet sebagai rasio arus lalu lintas (smp/jam) terhadap kapasitas (smp/jam) pada bagian jalan tertentu.

\section{Manfaat Penelitian}

Hasil penelitian ini diharapkan akan dapat memberikan informasi yang bermanfaat dalam perencanaan jaringan jalan perkotaan. Juga dapat dijadikan sebagai acuan dalam mengambil langkahlangkah untuk meningkatkan kapasitas dan kinerja jalan yang dimaksud, baik untuk masa sekarang maupun yang akan datangdengan harapan agar pada jalan Karet memberikan pelayanan yang baik dan maksimal

\section{Pembatasan Masalah}

Daerah atau lokasi penelitian ini adalah jalanKaret Palangka Raya. Jalan yang diteliti adalah jalan kota dua arah dua lajur tak terbagi. Segmen jalan yang diteliti dari STA $0+100$ - STA $0+200$ untuk mencari kapasitas, volume dan derajat kejenuhan di jalan Karet Palangka Raya, perhitungan berdasarkan Manual Kapasitas Jalan Indonesia (MKJI) tahun 1997 untuk jalan perkotaan

\section{HASIL DAN PEMBAHASAN}

\section{Analisis Volume LaluLintas}

Untuk penelitian terhadap kinerja jalan diperlukan data geometric jalan berupa lebar lajur, data lalu lintas untuk mengetahui derajat kejenuhan suatu segmen jalan.

Untuk mengetahui pengaruh jumlah hambatan samping (side friction) terhadap kapasitas jalan dan derajat kejenuhan di sepanjang segmen jalan yang diamati, dibutuhkan sejumlah data yang meliputi data jumlah kejadian hambatan samping berdasarkan tipe hambatan samping.

1. Pengambilan Data Lebar Jalur Lalu Lintas dan Data Lebar Bahu Jalan

Pengambilan data lebar jalur lalu lintas dan lebar bahu jalan ini dijalan karet. Dilaksanakan selama satu hari yaitu pada hari Senin, 8 Mei 2016. Alat yang digunakan yaitu meteran (50 meter), diambil setiap 100 meter.

\begin{tabular}{|c|c|c|c|c|c|}
\hline \multirow{2}{*}{ No } & \multirow{2}{*}{ Statiun } & \multirow{2}{*}{ Lebar Jalur Lalu Lintas } & \multicolumn{2}{|c|}{ Lebar bahu Jalan } & \multirow{2}{*}{ Rata -rata } \\
\cline { 4 - 6 } & & & Sisi A & Sisi B & \\
\hline 1 & $2+100$ & 5 & 2 & 2.4 & 2.2 \\
\hline 2 & $2+200$ & 5 & 2 & 2.4 & 2.2 \\
\hline \multicolumn{5}{|c|}{ Total rata-rata bahu jalan } & 2.2 \\
\hline
\end{tabular}

Sumber: hasil perhitungan

2. Pengambilan Data Volume LaluLintas

Pengambilan data lalu lintas dilaksanakan selama tiga hari, yaitu Senin 9 Mei 2016, Selasa 10 Mei 2016 dan Rabu 11 Mei 2016. Sistem yang digunakan adalah manual counter (tenaga manusia) dengan dibantu oleh alat pencacah (hand tally counter). Pencatatan jumlah kendaraan yang lewat ini dilaksanakan per 2 
jam yaitu pagi 2 jam, siang 2 jam dan sore 2 jam.

Pencatatan jenis kendaraan dikelompokkan pada

a) Kendaraan ringan (LV) termasuk mobil penumpang, mini bus, pick up dan jeep.

b) Kendaraanberat (HV) termasuktruck, dump truckdan bus.

c) Sepeda motor termasukkendaraanberodaduadantiga.

Berikutadalah data-data lalulintas yang ada di JalanKaret.

\section{AnalisisHambatanSamping}

1. MenghitungHambatanSamping

Pengambilan data hambatansampinginidilakukanbersamaandenganpen gambilan data volume lalulintasdengandaerahpengamatansepanjang 200 meter berdasarkanketentuan Manual KapasitasJalan Indonesia

(MKJI).Pengamatanfrekwensihambatansampingpada keduasegmenjalan yang diamatiberdasarkanpada

a) Jumlahpejalan kaki berjalanataumenyeberangsepanjangsegmenjalan.

b) Jumlahkendaraanberhentiatauparkir.

c) Jumlahkendaraanmasukdankeluarke/darilahansa mpingjalandansisijalan.

d) Aruskendaraan yang bergeraklambat, yaituarus total (kend/jam) darisepeda, pedati, traktordansebagainya.

Berikutadalah data hambatansamping yang ada di JalanKaret

\section{AnalisisKinerjaRuasJalan}

1. KecepatanArusBebas

a) Fvo $\rightarrow$ daritipejalan $2 / 2 \quad$ UD dankomposisikendaraan, makadidapatkannilaiFvountukmasing masingjeniskendaraan

Kendaraanringan $(\mathrm{LV}) \quad=44 \mathrm{Km} / \mathrm{jam}$

Kendaraanberat $(\mathrm{HV}) \quad=40 \mathrm{Km} / \mathrm{jam}$

Sepeda motor $(\mathrm{MC}) \quad=40 \mathrm{Km} / \mathrm{jam}$

b) $\mathrm{FVw} \rightarrow$ Dari tipejalan 2/2UD danlebarefektifjalurlalulintas $5 \mathrm{~m}$, berdasarkantabel 2.5 diketahuiFVw adalah-10

c) FFVsf $\rightarrow$ Dari tipejalan 2/2UD kelashambatansamping medium danlebarbahujalanefektif rata-rata adalah 2.2 m, berdasarkan tabel 2.6 diketahui FFVsf adalah 0,95

d) Dari jumlah penduduk kota 244.500 jiwa. Berdasarkan tabel 2.7 dapat diketahui FFVcs adalah 0,93

2. Perhitungan Arus Bebas Kendaraan

Kecepatan arus bebas kendaraan ringan (FVlv)

FVlv $\quad=(\mathrm{FVo}+\mathrm{FVw}) \times \mathrm{FFVsf} \times \mathrm{FFVcs}$

$=(44+-10) \times 0,95 \times 0,93$

$=30.03 \mathrm{Km} / \mathrm{jam}$

Kecepatan arus bebas kendaraan berat (FVhv)

$\mathrm{FFV}=\mathrm{FVo}-\mathrm{FVlv}$

$=44-30.03$

$=13.961 \mathrm{Km} / \mathrm{jam}$

FVhv $=$ FVhvo $-($ FFV $\times$ FVhvo $/ \mathrm{FVo})$

$=40-(13.961 \times 40 / 44)$

$=27.30 \mathrm{Km} / \mathrm{jam}$

Kecepatan arus bebas sepeda motor (MC)

$\mathrm{FVmc}=\mathrm{FVmco}-(\mathrm{FFV} \times \mathrm{FVmco} / \mathrm{FVo})$

$=40-(13.961 \times 40 / 44)$

$=27.30 \mathrm{Km} / \mathrm{jam}$

\section{AnalisisKinerjaRuasJalan}

1. KecepatanArusBebas

a) Fvo $\rightarrow \quad$ daritipejalan $2 / 2 \quad$ UD dankomposisikendaraan, makadidapatkannilaiFvountukmasing _ masingjeniskendaraan

Kendaraanringan $(\mathrm{LV}) \quad=44 \mathrm{Km} / \mathrm{jam}$

Kendaraanberat $(\mathrm{HV}) \quad=40 \mathrm{Km} / \mathrm{jam}$

Sepeda motor $(\mathrm{MC}) \quad=40 \mathrm{Km} / \mathrm{jam}$

b) $\mathrm{FVw} \rightarrow$ Dari tipejalan 2/2UD danlebarefektifjalurlalulintas $5 \mathrm{~m}$, berdasarkantabel $2.5 \quad$ diketahuiFVw adalah-10

c) FFVsf $\rightarrow$ Dari tipejalan 2/2UD kelashambatansamping medium danlebarbahujalanefektif rata-rata adalah 2.2 $\mathrm{m}, \quad$ berdasarkantabel $\quad 2.6$ diketahuiFFVsfadalah 0,95

d) Dari jumlahpendudukkota 244.500 jiwa. Berdasarkantabel dapatdiketahuiFFVcsadalah 0,93

2. Perhitungan Arus Bebas Kendaraan Kecepatan arus bebas kendaraan ringan (FVlv) FVlv $\quad=(F V o+F V w) \times$ FFVsf $\times$ FFV cs $=(44+-10) \times 0,95 \times 0,93$ $=30.03 \mathrm{Km} / \mathrm{jam}$ 
Analisa Kinerja Ruas Jalan Karet..., Faizal ${ }^{(1)}$, Nirwana ${ }^{(2)}$, Rida $^{(3)}$

Kecepatanarusbebaskendaraanberat (FVhv)

$$
\begin{aligned}
& \text { FFV = FVo }- \text { FVlv } \\
& =44-30.03 \\
& =13.961 \mathrm{Km} / \mathrm{jam}
\end{aligned}
$$

$\mathrm{FVhv}=\mathrm{FVhvo}-(\mathrm{FFV} \times \mathrm{FVhvo} / \mathrm{FVo})$

$=40-(13.961 \times 40 / 44)$

$=27.30 \mathrm{Km} / \mathrm{jam}$

Kecepatanarusbebassepeda motor (MC)

$\mathrm{FVmc}=\mathrm{FVmco}-(\mathrm{FFV} \times \mathrm{FVmco} / \mathrm{FVo})$

$=40-(13.961 \times 40 / 44)$

$=27.30 \mathrm{Km} / \mathrm{jam}$

\section{PEMBAHASAN}

Dari hasil perhitungan dengan data masukan seperti lebar jalur lalu lintas, lebar bahu jalan, volume lalu lintas dan derajat kejenuhan.

Nilai derajat kejenuhan yang terjadi pada segmen jalan yang diamati adalah berkisar antara $0,20-0,40$. Dari sini bisa dilihat bahwa derajat kejenuhannya masih terlihat bagus, karena derajat kejenuhan yang diperbolehkan maksimum adalah 0,85 . Dengan melihat derajat kejenuhan sebagai bahan pertimbangan untuk penilaian tingkat kinerja.Maka tingkat kinerja pada Jalan Karet Palangkaraya dalam keadaan baik.

Hasil dari perhitungan tersebut menyatakan tingkat atau kinerja pelayanan dari segmen jalan tersebut tidak terjadi masalah.

1. Hubungan Tingkat Kinerja dengan Hambatan Samping

Adanya hambatan samping pada jalur jalan akan mempengaruhi terhadap tinggi rendahnya tingkat kinerja suatu jalur jalan tersebut. Semakin tinggi kelas hambatan samping yang ada, akan memperendah tingkat kapasitas suatu ruas jalan yang menyebabkan menurunnnya tingkat kinerja suatu ruas jalan.

Jalan Jalan Karet Palangkaraya memiliki kelas hambatan samping yang sedang $(M)$.

2. Hubungan Tingkat Kinerja dengan Volume Lalu Lintas

Volume lalu lintas yang ada pada suatu jalur jalan akan mempengaruhi terhadap tinggi rendahnya tingkat kinerja suatu jalur jalan tersebut. Semakin tinggi volume lalu lintas dengan kapasitas yang ada maka derajat kejenuhan akan semakin bertambah.
Misalnya untuk pengamatan interval waktu 07.00-08.00 WIB (arus lalu lintas minimum) pada jalur jalan tersebut memberikan tingkat kinerja sebagai berikut.

Volume lalu lintas $\quad=368.6 \mathrm{smp} / \mathrm{jam}$

Kapasitas $\quad=1332.687 \mathrm{smp} / \mathrm{jam}$

Derajat kejenuhan $\quad=0,3$

Kondisi demikian akan berubah untuk pengamatan interval waktu 17.00-18.00 WIB (arus lalu lintas maksimum) pada jalur jalan memberikan tingkat kinerja sebagai berikut.

Volume lalu lintas $\quad=492.2833 \mathrm{smp} / \mathrm{jam}$

Kapasitas $\quad=1332.687 \mathrm{smp} / \mathrm{jam}$

Derajatkejenuhan $\quad=0,40$

Walaupun mempunyai perubahan DS dari 0.3 menjadi 0.4, akan tetapi kondisi tingkat kinerja ruas jalan masih sama yaitu tingkat B, yaitu arus stabil, tetapi kecepatan operasi mulai dibatasi oleh kondisi lalu lintas, pengemudi memiliki kebebasan yang cukup untuk menentukan kecepatan arus bebas.

\section{KESIMPULAN DAN SARAN}

1. Dari hasil survey lalu lintas ruas jalan dapat disimpulkan bahwa volume lalulintas pada jam puncak,

1) Pagi hari adalah $368.56 \mathrm{smp} / \mathrm{jam}$

2) Siang hari adalah $473.93 \mathrm{smp} / \mathrm{jam}$

3) Sore hari adalah $492.28 \mathrm{smp} / \mathrm{jam}$

Dan dari hasil survey geometri jalan, serta survey hambatan samping dan hasil analisis, dapat diketahui bahwa kapasitas ruas jalan adalah $1332.687 \mathrm{smp} / \mathrm{jam}$.

2. Berdasarkan hasil analisis dapat diketahui derajat jenuh (DS) ruas jalan karet pada jam puncak adalah :

1) Pagi hari adalah 0.30

2) Pada siang hari adalah 0.39

3) Pada sore hari adalah 0.40

Sehingga dapat disimpulkan bahwa tingkat kinerja pada ruas jalan karet termasuk kelas (B) dengan karakteristik Arus Stabil, tetapi kecepatan operasi mulai dibatasi oleh kondisi lalu lintas. Pengemudi memiliki kebebasan yang cukup untuk memilih kecepatan dengan kecepatan arus bebas $27.30 \mathrm{~km} / \mathrm{jam}$.

Kecepatan arus bebas pada ruas jalan tersebut adalah $:$ FVIv $=30.03 \mathrm{Km} / \mathrm{jam}$, Fvhu $=27.30$ $\mathrm{Km} / \mathrm{jam}, \mathrm{FVmc}=27.30 \mathrm{Km} / \mathrm{jam}$. 
Analisa Kinerja Ruas Jalan Karet..., Faizal ${ }^{(1)}$, Nirwana ${ }^{(2)}$, Rida $^{(3)}$

\section{Saran}

1. Perlu pengaturan dalam bentuk larangan berhenti, dan memasang rambu batas kecepatan maksimum karena didaerah pengamatan adalah daerah pertokoan.

2. Melakukan penertiban bagi para pengemudi kendaraan yang hendak parkir dibahu/badan jalan dan memberikan sangsi yang tegas bagi pengemudi yang melanggar.

Perlu ditambahkan rambu-rambu untuk pengemudi kendaraan yang hendak parkir agar tidak parker sembarangan di bahu jalan Yogyakarta 